\title{
Atmometer - based irrigation scheduling system for drip - irrigated onion (Allium cepa L.)
}

\author{
Cresan Joy Villaroman ${ }^{1+}$, Armando Espino $\mathrm{Jr}^{2}$., Jeffrey Lavarias ${ }^{2}$, and Victorino Taylan ${ }^{2}$ \\ ${ }^{1}$ Masteral Student of College of Engineering, Central Luzon State University and Faculty of Institute of Engineering and Applied \\ Technology, Bulacan Agricultural State College, San Ildefonso, Bulacan, Philippines ${ }^{2}$ Department of Agricultural and Biosystems \\ Engineering, Faculty of College of Engineering, Central Luzon State University, Science City of Muñoz, Nueva Ecija, Philippines
}

\begin{abstract}
This study was conducted to develop an atmometer-based irrigation scheduling system for drip-irrigated onion production. The study was conducted at San Agustin, San Jose City Nueva Ecija from November 2016 - March 2017. Three treatments composing of three replicates were considered in the research. Treatments 1 and 2 were based on the recorded atmometer readings with an irrigation interval of two days and five days respectively. Treatment 3 is a soil moisture-based irrigation scheduling with a management allowed deficit of $50 \%$. Calibration curved was obtained by comparing the atmometer readings with the estimated evapotranspiration using Modified Penman-Monteith equation. It was used in computing the crop water requirement for Treatments 1 and 2. The important parameters that used to answer the objective of the study such as plant height, crop yield, bulb weight, bulb diameter, water use and water productivity, were acquired during and after crop production. The statistical analysis used in the study was Analysis of Variance for Complete Randomized Design and paired T-test. Based on the result, Treatment 1 was highly useful in increasing water productivity without sacrificing the crop qualities.
\end{abstract}

\section{Introduction}

Bulb onion (Allium cepa) belongs to allium family which includes garlic and shallots. It is a popular vegetable widely grown throughout the world for its pungent bulbs and flavorful leaves. It was originated from Southeast Asia, but the wild progenitor has yet to be found ${ }^{[1]}$. The variety mostly used in the Philippines is the red "pinoy" and yellow onion. In year 2012, the total world production of dry bulb onion was $82,851,732$ MT and 4,342,135 MT for shallot and green onions. The largest producer of onion includes China, India, USA, Pakistan, and Turkey, wherein China and India accounted about $47 \%{ }^{[2]}$.

Water application affects the crop yield and production. Improper practice may lead to yield and quality reduction of the crop. Water management can be executed through irrigation scheduling. It does not only answer the question when to irrigate but also includes the estimation of how much water to be applied to achieve the maximum potential of crops ${ }^{[5]}$. Irrigation scheduling can be based on soil moisture and crop evapotranspiration (ET). Soil moisture - based irrigation scheduling was not applicable for large scale irrigation and requires additional work during installation.

ET-based irrigation scheme are based on empirical equation and weather data. The most common and recommended method by Food and Agriculture Organization (FAO) in estimating the crop ET was based on empirical equation which is the Modified PenmanMonteith equation. However, this method requires knowledge about the meteorological data which is indeed not common in all farmers.

The availability of the data is another problem in this method. Agrometeorological data are not always available in every local municipalities and the acquisition and installation of weather instruments in every locality was not possible because it was not economical.

An alternative tool in estimating the crop ET is through the use of atmometer or the electronic evapotranspiration gauge. This instrument was easy to install even in remote areas and the data collection does not requires complex work because it can be easily read in the sight tube. It also reduced the complexity of ETbased irrigation system.

The cost of one atmometer was also cheaper compared with the complete weather instruments. The technology could improve irrigation management while simplifying ET-based irrigation scheduling and it could give close estimate with the ET computed from weather station and is suitable for automated irrigation management in quantifying crop water needs ${ }^{[3]}$. It could also be used in area where there is no standard meteorological data available, it could be used in

\footnotetext{
${ }^{+}$Corresponding author: cresanjoyvv@gmail.com
} 
irrigation scheduling of both the farm and extension level ${ }^{[4]}$.

\section{Materials and method}

The experimental design was illustrated in Figure 1. Treatments 1 and 2 represents the two - day and five day irrigation interval based on atmometer readings. Treatment 3 is a soil moisture - based irrigation scheme with $50 \%$ management allowed deficit. The irrigation for the control is the farmers' practice which is flooding. Drip irrigation system was used to irrigate the experimental treatments. Buffer crops were used to lessen the error of the treatments.

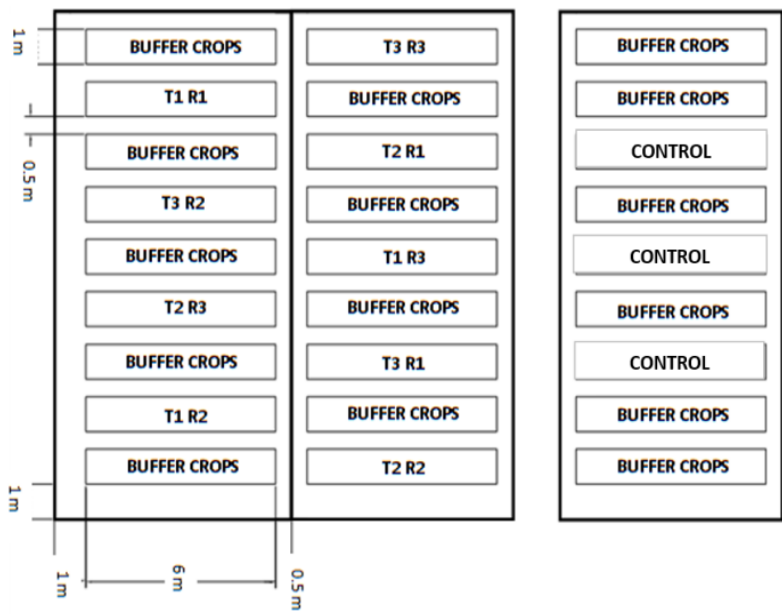

Fig. 1. Experimental layout

\subsection{Calibration of atmometer}

Atmometer is an instrument that estimates the crop $\mathrm{Et}_{0}$. The data can be obtained by simply looking in the sight tube. Other model of the instrument has a data logger wherein the data can be directly downloaded to a computer.

The estimated $\mathrm{Et}_{0}$ from the weather parameters were calculated using the Modified Penman-Monteith Equation $^{[6]}$ (Eq. 1).

$$
\mathrm{ET}_{\mathrm{o}}=\frac{0.048 \Delta\left(R_{n}-G\right)+\gamma \frac{900}{T+273} u_{2}\left(e_{s}-e_{a}\right)}{\Delta+\gamma\left(1+0.34 u_{2}\right)}
$$

The data from atmometer (Figure 2) was downloaded from the data logger attached to the instrument. It was compared and calibrated with the calculated $\mathrm{Et}_{\mathrm{o}}$ using the correlation and regression analysis to come up with a calibration curve and equation. It was used to compute the crop irrigation requirements for Treatment 1 and 2.

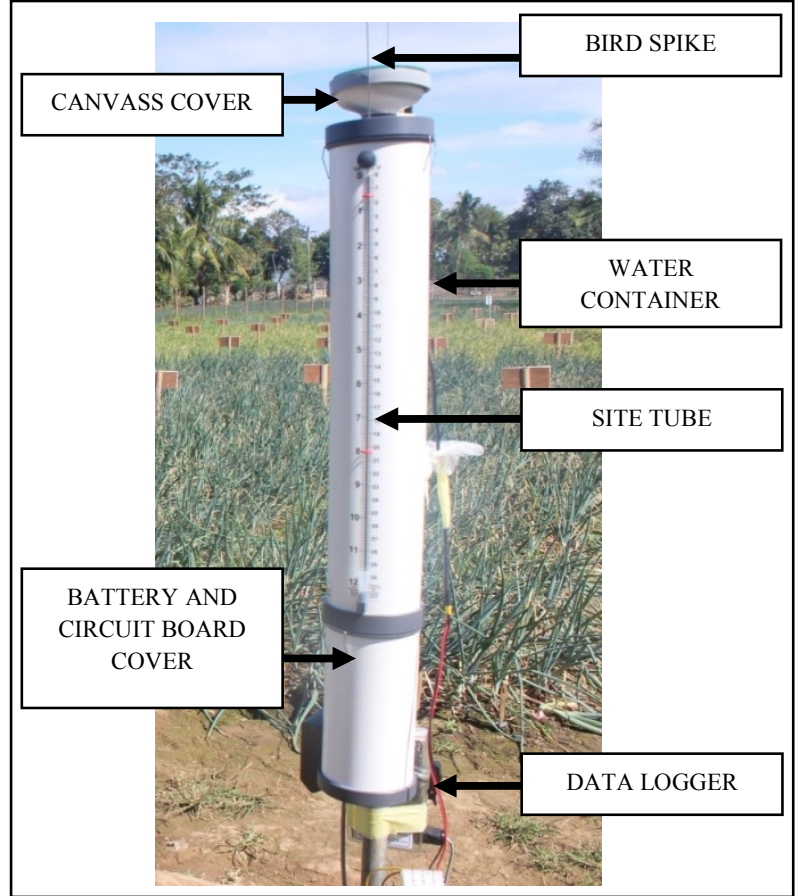

Fig. 2. Atmometer

\subsection{Crop Production}

The onion variety used for crop production is the "Red Pinoy" which is a standard short-day onion variety commonly used in the local municipality. The cultural practices followed in the study were seedlings preparation, land preparation, transplanting, fertilizer application, weeds and pests control, and harvesting. The study used three irrigation treatments as mentioned before.

\subsection{Parameters of the study}

In order to achieve the objectives of the study, the following data was gathered: atmometer reading, agrometeorological data, soil moisture behavior, plant height, total volume of water, crop yield, bulb diameter, bulb weight and other observations.

\subsection{Statistical analysis}

The experimental design of the study was Complete Randomized Design (CRD). It was used to compare the three experimental treatments to identify the significant difference within the treatments with a 0.05 probability levels. The experimental treatments were also compared with the control using the paired T-test to see the response of onion in different irrigation scheme. 


\section{Results and discussion}

\subsection{Calibration of atmometer}

The generated equation for the calibration of atmometer with the Modified Penman-Monteith equation was:

$$
y=0.688 x+1.522
$$

The independent variable was the atmometer readings and the dependent variable was the computed evapotranspiration (ET) from the weather data using Modified Penman-Monteith equation.

Figure 3 shows the computed ET and atmometer readings during crop production. A correlation value of 0.89 that was calculated was substantial considering that the distance between the experimental site and adjacent weather station was about $15 \mathrm{~km}$.

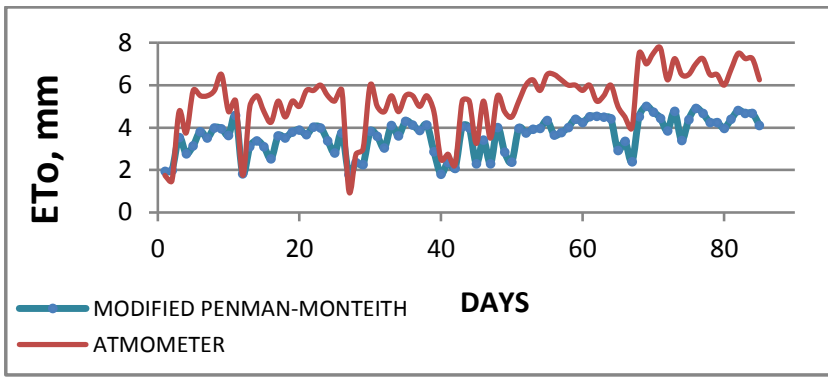

Fig 3. ETo estimated from atmometer and weather data

\subsection{Plant height}

The generated Weekly plant height was monitored starting from 30 days after transplanting until approximately one week before the harvest. Highest growth rate was observed in farmers' practice compared with other treatments which portrayed almost uniform growth rate. In general, all treatments showed the same growth behaviour as shown in figure 4 .

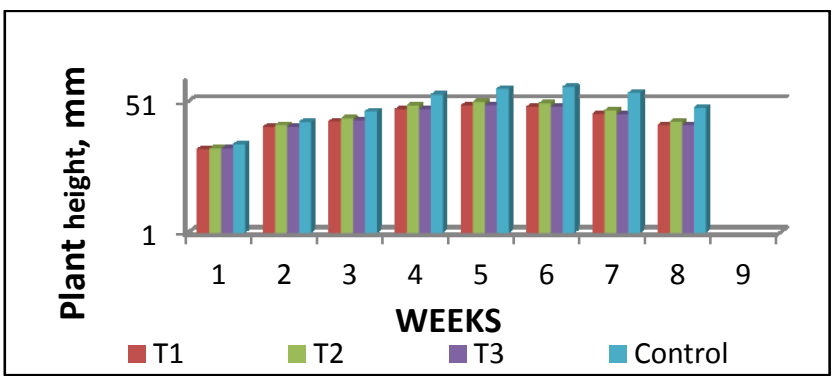

Fig 4. Weekly plant height of onion

\subsection{Crop yield}

The tabulation of average crop yield per hectare was represented by table 1 . The crop yield data gathered in the study undergo statistical analysis and the result shows no significant difference between the treatments. However, the result of the comparison of the treatments with the control reveals that Treatment 1 does not affect the yield.
Table 1. Computed yield, tons per hectare.

\begin{tabular}{|c|c|c|c|c|}
\hline Treatment & $\mathbf{R}_{\mathbf{1}}$ & $\mathbf{R}_{\mathbf{2}}$ & $\mathbf{R}_{\mathbf{3}}$ & MEAN \\
\hline $\mathrm{T}_{1}$ & 30.75 & 32.50 & 37.50 & $33.58^{\mathrm{NS}}$ \\
\hline $\mathrm{T}_{2}$ & 29.50 & 26.50 & 30.50 & $28.83^{*}$ \\
\hline $\mathrm{T}_{3}$ & 32.50 & 34.00 & 27.00 & $31.17^{*}$ \\
\hline Control & 37.50 & 38.00 & 29.00 & 34.83 \\
\hline
\end{tabular}

\subsection{Bulb diameter}

The onion bulbs were classified into three groups based on the size which is small, medium and large according to the Philippine National Standard (PNS). The measured average diameter of bulb onion was listed in Table 2. The comparison of treatments with the control shows that the bulb diameter in control was significantly larger than the Treatment 2 while Treatments 1 and 3 does not affect the bulb size of onion.

Table 2. Average bulb diameter, $\mathrm{cm}$

\begin{tabular}{|c|c|c|c|c|}
\hline Treatment & $\mathbf{R}_{\mathbf{1}}$ & $\mathbf{R}_{\mathbf{2}}$ & $\mathbf{R}_{\mathbf{3}}$ & MEAN \\
\hline $\mathrm{T}_{1}$ & 4.31 & 4.35 & 4.65 & $4.44^{\mathrm{NS}}$ \\
\hline $\mathrm{T}_{2}$ & 4.40 & 4.33 & 4.34 & $4.36^{*}$ \\
\hline $\mathrm{T}_{3}$ & 4.30 & 4.42 & 4.57 & $4.43^{\mathrm{NS}}$ \\
\hline Control & 4.55 & 4.57 & 4.59 & 4.57 \\
\hline
\end{tabular}

\subsection{Bulb weight}

The individual bulb weight of the onion was also identified in the study with the use of digital weighing scale ( $1 \mathrm{~g}$ sensitivity). The average bulb weight of the treatments was shown in Table 3. The result of paired $\mathrm{T}$-test reveals that control was significantly heavier in terms of average bulb weight than Treatment 2 while the other treatments yield no significant difference with the control. 
Table 3. Average bulb weight, $g$

\begin{tabular}{|c|c|c|c|c|}
\hline Treatment & $\mathbf{R}_{\mathbf{1}}$ & $\mathbf{R}_{\mathbf{2}}$ & $\mathbf{R}_{\mathbf{3}}$ & MEAN \\
\hline $\mathrm{T}_{1}$ & 37.60 & 42.23 & 48.63 & $42.82^{\mathrm{NS}}$ \\
\hline $\mathrm{T}_{2}$ & 40.00 & 39.60 & 41.13 & $40.24^{*}$ \\
\hline $\mathrm{T}_{3}$ & 38.53 & 43.30 & 45.90 & $42.58^{\mathrm{NS}}$ \\
\hline Control & 50.10 & 45.27 & 50.97 & 48.78 \\
\hline
\end{tabular}

\subsection{Water productivity}

Table 4 is the tabulation of the average water productivity. It showed that Treatments 1, 2 and 3 have considerable increase in water savings as compared with the control unit.

\subsection{Uniformity distribution}

The uniformity distribution in every treatment was tabulated in Table 5. Based on the statistical analysis there is no variation between the Treatment 1 and control in terms of bulb uniformity. On the other hand, Treatments 2 and 3 produced more uniform onion bulbs than control.

Table 4. Water productivity, $\mathrm{kg} / \mathrm{m}^{3}$

\begin{tabular}{|c|c|c|c|c|}
\hline Treatment & $\mathbf{R}_{\mathbf{1}}$ & $\mathbf{R}_{\mathbf{2}}$ & $\mathbf{R}_{\mathbf{3}}$ & MEAN \\
\hline $\mathrm{T}_{1}$ & 7.91 & 8.35 & 9.64 & $8.63^{*}$ \\
\hline $\mathrm{T}_{2}$ & 7.19 & 6.46 & 7.44 & $7.03^{*}$ \\
\hline $\mathrm{T}_{3}$ & 11.89 & 12.44 & 9.88 & $11.40^{*}$ \\
\hline Control & 1.90 & 1.93 & 1.47 & 1.77 \\
\hline
\end{tabular}

Table 5. Water productivity, $\mathrm{kg} / \mathrm{m}^{3}$

\begin{tabular}{|c|c|c|c|c|}
\hline Treatment & $\mathbf{R}_{\mathbf{1}}$ & $\mathbf{R}_{\mathbf{2}}$ & $\mathbf{R}_{\mathbf{3}}$ & MEAN \\
\hline $\mathrm{T}_{1}$ & 90.42 & 86.77 & 87.83 & $88.34^{\mathrm{NS}}$ \\
\hline $\mathrm{T}_{2}$ & 92.22 & 93.16 & 91.79 & $92.39^{*}$ \\
\hline $\mathrm{T}_{3}$ & 89.66 & 90.00 & 89.33 & $89.66^{*}$ \\
\hline Control & 86.17 & 88.26 & 85.76 & 86.73 \\
\hline
\end{tabular}

\subsection{Other observations}

Pungency of the onion determines it's sharpness of smell and taste. The higher the value means the stronger the taste and smell of the onion. Based on ANOVA results, it revealed that there is no significant difference within the treatments.

The color of onion bulb was determined through physical observations. It was divided into different categories (red, pink, red with pink) depending on variation of colors. The most common color of onion was red, followed by red with pink and the least was pink.

The bulb shape was categorized into five types (round, elongated, deformed, split, and, round and elongated) by means of physical observation. The least frequent is the split and the most frequent was circle.

\section{Conclusion}

Based on the results of the study, the following conclusions were drawn: 1) more uniform - sized bulb can be produced under drip irrigation system, 2) the use of treatment 1 increase water savings without sacrificing the crop quality; and, 3) atmometer can be a substitute for automatic weather station in managing irrigation scheme based on crop evapotranspiration and it can be used in large scale irrigation system.

This study will not be possible without the financial support from the Department of Science and Technology - Science Education Institute (DOST - SEI), through the Engineering Research and Development for Technology (ERDT) scholarship grant.

\section{References}

1. K. Adam, Organic allium prod., Natl sustainable agric. info. service (2006)

2. Department of Agriculture Luzon A Cluster, Val. chain analysis and competitiveness strategy: Bulb onion, Phil. rural devt proj. (2014)

3. S. Irmak, J.O. Payero, D.L. Martin, Using modified atmometers (ET gage) for irri. mngt. (2005)

4. V. Magluilo, R. d'Andria, G. Rana, The modified atmometer: a useful tool to estimate Eto in mediterranean environment, (2002)

5. E. Martin, Methods of measuring for irri. scheduling-when, 30, (2009)

6. L. Zotarelli, M. Dukes, C. Romero, K. Migliaccio, K. Morgan, Step by step calc. of the PenmanMonteith Evapotranspiration (FAO - 56 Method), (2015) 